\title{
Care Management Challenges for Diabetic Foot Ulcers: A Qualitative Study
}

\author{
Sefollah Alaei (iD ${ }^{1}$, Hesamedin Askari Majdabadi (iD) ${ }^{1,}$, Shahrokh Khojastehfar ${ }^{2}$ and Narges \\ Pourhashemi ${ }^{3}$ \\ ${ }^{1}$ Nursing Care Research Center, Semnan University of Medical Sciences, Semnan, Iran \\ ${ }^{2}$ Kosar Hospital, Semnan University of Medical Sciences, Semnan, Iran \\ ${ }^{3}$ Nursing Student Research Center, Semnan University of Medical Sciences, Semnan, Iran \\ "Corresponding author: Nursing Care Research Center, Semnan University of Medical Sciences, Semnan, Iran. Email: hesamaskari@yahoo.com
}

Received 2020 July 05; Revised 2022 January 08; Accepted 2022 January 09.

\begin{abstract}
Background: Diabetes mellitus, if is not well taken care and treated, may exacerbate complications such as ulcers, infections, and amputations. Accordingly, preventive measures and timely treatment are of paramount importance.

Objectives: This study sought to collect profound experiences about diabetic ulcer care management with an emphasis on community-based care.

Methods: The study was carried out using the qualitative content analysis method during 2017 - 2018 in Semnan Province, Iran. The study encompassed 14 participants, including six caregivers, two family members, one nurse, one nursing supervisor, one manager of counseling and nursing care service centers (CNCSCs), one head nurse, and two physicians, who were selected using the purposive sampling method. The analysis process was performed based on Graneheim and Lundma's approach.

Results: Two main categories were as follows: (1) "Dispersion in preventive measures," with subcategories of "vague perception of disease symptoms', 'inability in self-management' and 'low-efficient preventive care', and (2) "Gradual access to outpatient services" with subcategories of 'gradual expansion of outpatient ulcer care', 'complexity of financial transactions', 'improving inter-sectoral cooperation' and 'ambiguous professional boundaries'.

Conclusions: Care facilities offering services to diabetic foot ulcers, especially community-based nursing care centers, are gradually expanding, and new wound care methods are being adopted. However, lack of self-care management, insufficient support, treatment-oriented approaches, and all clients' insufficient access to these services are some of the problems that still exist in the care management of diabetic ulcers.
\end{abstract}

Keywords: Care Management, Diabetes Complications, Diabetes Foot Ulcer, Challenges

\section{Background}

Diabetes mellitus (DM) is a serious, long-term disease with a major impact on the well-being of individuals, families, and societies worldwide. Diabetes claims for four million deaths per year (1), and its prevalence is rising to $10.2 \%$ (578 million persons) by 2030 and 10.9\% (700 million persons) by 2045 (2). This rising trend is attributed to aging, obesity, hypertension, immigration, and urbanization (3). In line with the increasing prevalence of diabetic mellitus in the world (2), Iran is also experiencing an increase in the risk factors of diabetes, including aging $(4,5)$ and lifestylerelated factors (6).

Diabetes, if left untreated, may lead to relapses, sideeffects, and more severe complications such as ulcers and infections (7). The improper management of diabetic foot ulcers (DFU) eventually leads to amputation (8) and its relevant problems, including reduced quality of life and economic burdens (9-12). Accordingly, preventive measures and timely treatment are of great significance (13).

About 60\% (14) of patients suffer from some degree of amputation. Mortality rates associated with developing a diabetic ulcer (DU) are estimated to be $5 \%$ in the first 12 months and $42 \%$ in five years (15). Diabetes complications may lead to long-term hospitalization (16), progressive therapy (17), and even death (18). To save limited hospital resources and given the preferences for prevention, the development of community-based care management is considered a priority $(19,20)$. Care management is defined as "a set of activities designed to assist patients and their support systems in managing medical conditions and relevant psychosocial problems more effectively" (21). 
Care management dates back to the 21st century, which was introduced to solve the dichotomy between management and care delivery in practices (22). To address the burden management of chronic diseases such as diabetes effectively and equitably, integrated approaches must be applied in strategies and interventions (23) proposed in some other studies $(24,25)$.

In this regard, the DFU care management encompassing outpatient care, self-management, and prompt treatment (9), could reduce the need for hospitalization (26). Good glycemic control and active investigation against the peripheral arterial disease (PAD) are important in reducing infection and amputation risks (27). Beiranvand's study shows that despite patients and families' positive attitudes, they have poor knowledge and care performance (28). Socio-cultural factors influence selfmanagement; therefore, policy-makers and care providers must re-evaluate this process (29). To improve diabetes management, multidisciplinary teams are added to the prevention and treatment process (30). The National Diabetes Prevention and Control Program is implemented in Iran for the early diagnosis and appropriate treatment (31, 32 ). One relevant study showed that this program positively influenced participants (33).

Accordingly, it is necessary to obtain adequate information about diabetes care management, the consequences of relevant programs and care challenges, and factors affecting wound creation. Researchers have decided to explore the experiences of patients, families, managers, and care providers about DU; hence a qualitative study seems necessary to understand the depth of their experiences.

\section{Objectives}

This study sought to collect profound experiences about diabetic ulcer care management with an emphasis on community-based care.

\section{Methods}

\subsection{Research Design}

This research was carried out using the qualitative content analysis method during 2017 - 2018, in Semnan Province, Iran.

\subsection{Participants}

The main participants included those suffering from diabetic ulcers, who were willing to share their experiences, and another group of participants were purposefully selected based on the extracted data. The participants were ensured of information confidentiality and their voluntary participation in the study. In this regard, their informed written consent forms were collected. Fourteen participants were purposively selected from CNCSCs, outpatient clinics, physician offices, and hospitals according to the data (Table 1). The participants who were chosen from community-based care centers and hospitals, either as clients or care service providers, played a critical role in the DFU care management process.

\begin{tabular}{|c|c|c|c|c|}
\hline No. & Gender & Age & $\begin{array}{c}\text { Individual or } \\
\text { Organizational } \\
\text { Characteristic }\end{array}$ & $\begin{array}{l}\text { Work Experiences or } \\
\text { Provided Services (y) }\end{array}$ \\
\hline $\mathbf{1}$ & $\mathrm{F}$ & 58 & Patient-housekeeper & 2 \\
\hline 2 & $\mathrm{~F}$ & 48 & Patient-office clerk & 1 \\
\hline 3 & M & 75 & Patient-retired & 15 \\
\hline 4 & M & 29 & Family member & 2 \\
\hline 5 & $\mathrm{~F}$ & 59 & Patient-housekeeper & 1.5 \\
\hline 6 & $\mathrm{~F}$ & 34 & Family member & 1 \\
\hline 7 & M & 57 & Patient- retired & 7 \\
\hline 8 & M & 61 & Patient- car driver & 3 \\
\hline 9 & M & 48 & CNCSCs manager & 27 \\
\hline 10 & $\mathrm{~F}$ & 45 & Nursing care provider & 10 \\
\hline 11 & $\mathrm{~F}$ & 38 & Head nurse & 17 \\
\hline 12 & M & 40 & Nursing care provider & 14 \\
\hline 13 & M & 37 & General practitioner & 11 \\
\hline 14 & M & 50 & Specialist physician & 25 \\
\hline
\end{tabular}

\subsection{Data Collection}

The data were collected using some general questions such as "how did you recognize the emergence of the ulcer?" Interviews were followed with some semi-structured questions as follows: "what did you do after recognizing the ulcer?", "can you explain more about the follow-up of ulcer treatment?" or "what do you mean by ulcer care?" (34). The interviews lasted from 25 to 65 minutes, with an average of 40 minutes. Data collection continued as long as hidden data were discovered, and no new code was extracted.

\subsection{Data Analysis}

During the data collection phase, the data analysis process was also performed according to Graneheim and Lundman's five-step approach (35). In this regard, interviews were transcribed verbatim. To be immersed in the data, the researcher listened to the interviews and reviewed the text of the manuscripts several times to extract 
the meaning units from the participants' statements and specify them in the form of codes (ie, meaning units). The codes were also classified based on semantic and conceptual similarity and became concise as much as possible (ie, abstracting). The units of analysis and their subcategories were decreased (ie, sorting). Finally, the data were placed in the main categories, which were more general and conceptual, and the themes were abstracted (ie, formulating themes).

Meanwhile, Guba and Lincoln's criteria were used to reinforce the rigor of data (36). To evaluate the credibility of the findings, the extracted codes were checked by some participants and modified if necessary. The researchers had prolonged engagement and spent about two years collecting and analyzing data. To assess confirmability, all the interview texts, the codes, and categories were reviewed and approved by the authors and two faculty members, who were not the research team members. To confirm dependability, the research steps were recorded accurately in detail. The participants were selected with maximum variation to observe acceptability and transferability.

\section{Results}

Table 1 shows the participants' characteristics in studying care management challenges for DFU.

Most participants had diabetes for about ten years, and they had been affected by diabetes ulcers at least once or twice. Two main categories emerged in this study were as follows:

(1) "Dispersion in preventive measures" with the following subcategories: 'vague perception of disease symptoms', 'inability in self -management' and 'low-efficient preventive care',

(2) "Gradual access to outpatient services" with the following subcategories: 'gradual expansion of outpatient ulcer care', the' complexity of financial transactions', 'improving inter-sectorialsectoral cooperation' and 'ambiguous professional boundaries' (Table 2).

\subsection{Dispersion in Preventive Measures}

According to participants' experiences, several factors cause diabetes ulcers, the most important of which are carelessness and physical injuries. Moreover, the severity of these symptoms fluctuates and sometimes increases and sometimes decreases. In general, patients' statements were ambiguous about the onset of symptoms.

" To some extent, I could not feel my feet while wearing socks. I ignored my toes until I saw an ulcer between them" (A patient No. 8).

The improper examination of vulnerable parts and insufficient attention to the symptoms can increase the

\begin{tabular}{|c|c|c|}
\hline $\begin{array}{l}\text { Main Category } \\
\text { (Theme) }\end{array}$ & Category & Subcategory \\
\hline \multirow{8}{*}{$\begin{array}{l}\text { Dispersion in } \\
\text { preventive measures }\end{array}$} & \multirow{3}{*}{$\begin{array}{l}\text { A vague perception of } \\
\text { disease symptoms }\end{array}$} & $\begin{array}{l}\text { Exacerbation of } \\
\text { disease caused by } \\
\text { comorbidities }\end{array}$ \\
\hline & & $\begin{array}{l}\text { Variety of underlying } \\
\text { factors in the onset of } \\
\text { symptoms }\end{array}$ \\
\hline & & $\begin{array}{l}\text { Intermittent onset of } \\
\text { symptoms }\end{array}$ \\
\hline & \multirow{2}{*}{$\begin{array}{l}\text { Inability in } \\
\text { self-management }\end{array}$} & $\begin{array}{l}\text { superficial familiarity } \\
\text { of patient and his/her } \\
\text { family about care and } \\
\text { drugs }\end{array}$ \\
\hline & & $\begin{array}{l}\text { Late awareness of } \\
\text { onset of diabetic ulcer } \\
\text { symptoms }\end{array}$ \\
\hline & \multirow{3}{*}{$\begin{array}{l}\text { Low efficient } \\
\text { preventive care }\end{array}$} & $\begin{array}{l}\text { Recurrence of ulcer by } \\
\text { injuries }\end{array}$ \\
\hline & & $\begin{array}{l}\text { Exacerbation of } \\
\text { symptoms due to } \\
\text { inadequate prevention } \\
\text { measures }\end{array}$ \\
\hline & & $\begin{array}{l}\text { Hospitalization due to } \\
\text { inadequacy of } \\
\text { outpatient care } \\
\text { measures }\end{array}$ \\
\hline \multirow{9}{*}{$\begin{array}{l}\text { Gradual access to } \\
\text { outpatient services }\end{array}$} & \multirow{2}{*}{$\begin{array}{l}\text { Gradual expansion of } \\
\text { outpatient services of } \\
\text { ulcer care }\end{array}$} & $\begin{array}{l}\text { Relative expansion of } \\
\text { nurses' capabilities in } \\
\text { ulcer care }\end{array}$ \\
\hline & & $\begin{array}{l}\text { Gradual expansion of } \\
\text { outpatient centers of } \\
\text { ulcer care }\end{array}$ \\
\hline & \multirow{3}{*}{$\begin{array}{l}\text { Complexity of } \\
\text { financial transactions }\end{array}$} & $\begin{array}{l}\text { Gradual transparency } \\
\text { of tariffs }\end{array}$ \\
\hline & & $\begin{array}{l}\text { Complaints about } \\
\text { costs of outpatient } \\
\text { services }\end{array}$ \\
\hline & & $\begin{array}{l}\text { Expansion of } \\
\text { insurance coverage for } \\
\text { wound care }\end{array}$ \\
\hline & \multirow{2}{*}{$\begin{array}{l}\text { Improving } \\
\text { inter-sectorial } \\
\text { cooperation }\end{array}$} & $\begin{array}{l}\text { Increase in referrals of } \\
\text { patient to nursing } \\
\text { centers }\end{array}$ \\
\hline & & $\begin{array}{l}\text { Gradual tendency of } \\
\text { physicians to refer } \\
\text { patients to nursing } \\
\text { centers }\end{array}$ \\
\hline & \multirow{2}{*}{$\begin{array}{l}\text { Ambiguous } \\
\text { professional } \\
\text { boundaries }\end{array}$} & $\begin{array}{l}\text { Ambiguity in activity } \\
\text { boundaries }\end{array}$ \\
\hline & & $\begin{array}{l}\text { Focus of patient and } \\
\text { family's demands on } \\
\text { general ulcer care }\end{array}$ \\
\hline
\end{tabular}


severity of ulcers. Lack of training for patients and their family was the main cause of inappropriate selfmanagement.

"... they (patients or families) do not receive enough training about the early symptoms of ulcers. Even when the ulcer is emerged, they treat it in their own way even though they do not have appropriate skills in this case" (A medical specialist No. 14).

In addition to nurses and physicians, many patients report that ulcer care is provided based on personal interest or others' suggestions. This issue may sometimes even lead to a favorable outcome; however, the infection is exacerbated in many cases.

"Last time, my toes were ulcerated, and I poured dry tea leaf on them because I had heard it was useful, and sometimes I dried ulcers by a hairdryer, which provided acceptable results. However, I have recently tried them several times, the ulcer got deteriorated, and I went to the doctor" (A patient No 7).

\subsection{Gradual Access to Outpatient Services}

Outpatient services for diabetic ulcer care in clinics, doctors' offices, and even patients' homes are significantly expanding. Referral to CNCSCs is based on the recommendations of the physician and some members of the treatment team, following the initial or even after long-term ineffective ulcer management. Despite the communitybased activities of nurses, they do not focus on prevention. Patients and families are not eager for classical education and sometimes refer to web-based information. They are not familiar with nurses' abilities and do not trust them completely.

"I was not familiar with CNCSCs providing care for the ulcer. When I was going to the doctor's office, I saw its sign, but I did not think they could help so much until the doctor referred me to them" (A patient No. 3).

The specialized nursing care centers are gradually developing, and inter-sectorial interactions of health providers are expanding; however, unfamiliarity with other care providers and negative competition slow down this process.

"The work agreement has been formed between nursing centers and some hospitals, but until now, it has not been well implemented..." (a manager of CNCSCs No. 9).

Another point is that hospital admissions for other medical reasons, such as fractures or injuries, sometimes cause inconsistency and negatively impact the ulcer healing process.

"My father was admitted for a fracture of the leg and, because of the focus on the fracture, unfortunately, they (the therapeutic team) neglected to take enough care of the previous ulcer" (A family member No. 4).
Insurance coverage is expanding; however, there exist some problems, especially for new dressing cost coverage, leading to low affordability and dissatisfaction. However, some of these care providers' failure to comply with financial fairness also contributes to this situation.

"Despite its effectiveness and rapid recovery, the new dressing method really does not do it, mainly because it is not covered by insurance as such I sometimes need the family to provide dressing materials" (A nurse No.10).

In some cases, the patient and his/her family do not recognize the legal boundaries of the nurse and the physician's activities. These ambiguities even lead to problems such as complaints to the court.

"By the advice of one of my relatives, I went to one of the nursing centers. The nurse working there immediately began to debride the ulcer surface using a saw-like machine. After that, I felt the ulcer was getting worsened, and I did not go there anymore. I even wanted to complain about it" (A patient No. 7).

Nursing centers spare efforts to receive advice from physicians and sometimes introduce themselves as technical assistants; however, this cannot completely resolve ambiguous legal problems.

\section{Discussion}

The findings revealed that low prevention infrastructures and behaviors lead to creating ulcers, inadequate care, delays in referring to specialized centers, and eventually hospitalization. Fortunately, various communitybased services have been reinforced in the DU care. Similar to Gitarja's study in Indonesia (24), developing the role of nurses in new ulcer care methods is effective and promising. However, treatment-oriented approaches, insufficient trust in nurses, and some legal issues negatively influence prevention, referral, and care processes. Smith-Strom et al. found out that timely diagnosis, the rapid pursuit of the healing process, and the referral of patients were critical for diabetic foot ulcer management (37). Our study indicated that patients and families pay not enough attention to ulcer signs, and even after ulceration, they focus on improper self-management in many cases. In line with the present study, Abbas in Africa showed that defective self-medication and late referrals to health care centers were some of the challenges in managing diabetes wound care (25). The low supervision of health care providers on this process usually leads to exacerbated and prolonged treatment. Other studies also show that improper selfmanagement is one of the main causes of inadequate care. Accordingly, self-care and herbal therapy should be done scientifically despite their usefulness. Few adverse effects can be achieved through careful diagnosis and follow-up 
in the form of primary care and by facilitating timely access to more specialized care services (38).

In contrast to the weakness of outpatient services, hospitalization (39), the improper care management strategy (38), and amputations (40) in developing countries, outpatient services for ulcer care are acceptable in Iran. However, in comparison to developed countries (19), they are slowly going toward team-work formation. Meanwhile, previous studies have indicated that nursing care is mainly based on work experiences (41). Improving nurses' and paramedics' knowledge in the academic and working process is one of the requirements in improving the quality of patient care (42). This issue was emphasized in Abass's study despite poor infrastructures (25).

Participatory approaches and new technologies have effectively established an association between patients and families and physicians and nurses in improving and families' care management abilities (43). Like developed countries, these positive approach would lead to multidisciplinary and preventive approaches in our country (44).

Unlike developing countries (24), insurance coverage is expanding; however, financial interactions are still complicated and accompanied by restrictions such as inadequacy in covering outpatient treatment and medications (45). Accordingly, the transparency of financial transactions and an increase in insurance coverage can effectively increase the affordability of community-based DUC services.

\subsection{Limitations}

Given the qualitative study method, the generalization of the findings to other care environments and conditions is limited. Furthermore, the lack of access to private hospitals may be another limitation of this study.

\subsection{Conclusions}

Even though the self-care capacity of patients and families is not at the desired level, the development of the care capacity, especially among nurses, and the use of new care methods are considered as acceptable techniques. However, this situation should be reinforced by creating holistic approaches and applying existing capacities. To achieve optimal and preventive community-based care, there is a need to raise public awareness, improve legal infrastructure, and clarify the professional domain of activities. In addition to the preventive measures, technology and facilities should be utilized for the timely diagnosis, care, and referral of patients.

\section{Footnotes}

Authors' Contribution: Study concept and design: Seffolah Alaei and Hesamodin Askari-Majdabadi; Data collection: Narges Pourhashemi and Shahrokh Khojastehfar; Data analysis: Shahrokh Khojastehfar; Manuscript drafting: Seffolah Alaei and Hesamodin Askari-Majdabadi; Critical revision of the manuscript for important intellectual content: Seffolah Alaei and Hesamodin Askari-Majdabadi.

Conflict of Interests: The authors declare that they have no conflict of interest.

Ethical Approval: IR.SEMUMS.REC.1394.50.

Funding/Support: This study was financially supported by the Research Deputy of the Semnan University of Medical Sciences.

Informed Consent: The participants were ensured of information confidentiality and voluntary participation in the study. In this regard, their informed written consent was also obtained.

\section{References}

1. International Diabetes Federation. IDF Diabetes Atlas. 8th ed. Brussels, Belgium: International Diabetes Federation; 2017.

2. Saeedi P, Petersohn I, Salpea P, Malanda B, Karuranga S, Unwin N, et al. Global and regional diabetes prevalence estimates for 2019 and projections for 2030 and 2045: Results from the International Diabetes Federation Diabetes Atlas. Diabetes Res Clin Pract. 2019;157:107843. doi: 10.1016/j.diabres.2019.107843. [PubMed: 31518657].

3. Thibault V, Belanger M, LeBlanc E, Babin L, Halpine S, Greene B, et al. Factors that could explain the increasing prevalence of type $2 \mathrm{di}$ abetes among adults in a Canadian province: a critical review and analysis. Diabetol Metab Syndr. 2016;8:71. doi: 10.1186/s13098-016-01869. [PubMed: 27833664]. [PubMed Central: PMC5103368].

4. Khodamoradi A, Hassanipour S, DaryabeigiKhotbesara R, Ahmadi B. The trend of population aging and planning of health services for the elderly: A review study. J Torbat Heydariyeh Univ Med Sci. 2018;6(3):8195.

5. Valinejadi A, Sadoughi F, Salehi M. Diabetes Knowledge Translation Status in Developing Countries: A Mixed Method Study Among Diabetes Researchers in Case of Iran. Int J Prev Med. 2016;7:33. doi: 10.4103/2008-7802.175992. [PubMed: 26955462]. [PubMed Central: PMC4763462].

6. Hajian-Tilaki K. Metabolic syndrome and its associated risk factors in Iranian adults: A systematic review. Caspian J Intern Med. 2015;6(2):51. [PubMed Central: PMC4478451].

7. Frykberg RG, Banks J. Management of diabetic foot ulcers: a review. Fed Pract. 2016;33(2):16. [PubMed Central: PMC6368931].

8. Geiss LS, Li Y, Hora I, Albright A, Rolka D, Gregg EW. Resurgence of Diabetes-Related Nontraumatic Lower-Extremity Amputation in the Young and Middle-Aged Adult U.S. Population. Diabetes Care. 2019;42(1):50-4. doi: 10.2337/dc18-1380. [PubMed:30409811].

9. Liu J, Lu Q, Pang D, Yang P, Jin S, Yuan G, et al. Foot Care Education Among Patients With Diabetes Mellitus in China: A Crosssectional Study. J Wound Ostomy Continence Nurs. 2020;47(3):276-83. doi: 10.1097/WON.0000000000000653. [PubMed: 32384530].

10. Shojaei S, Yousefi M, Ebrahimipour H, Valinejadi A, Tabesh H, Fazaeli S. Catastrophic health expenditures and impoverishment in the households receiving expensive interventions before and after health sec- 
tor evolution plan in Iran: Evidence from a big hospital. Koomesh. 2018:283-90.

11. Fazaeli AA, Fazaeli AA, Hamidi Y, Moeini B, Valinejadi A. Analysis of iranian household financial participation in the health system: decomposition of the concentration index approach. Koomesh. 2018:358-68.

12. Yousefi M, Aliani S, Valinejadi A, Rezazadeh A, Khorsand A, Fazaeli S. Effect of Iran's health system evolution plan and tariff change on financial performance of para-clinic units in a big tertiary hospital in Iran. Koomesh. 2018;20(2)

13. Stevens LK. Effectiveness of a foot self-management intervention that utilized commercially available infrared thermometers: a patient-oriented research and mixed methods research study. Memorial University of Newfoundland; 2020.

14. Al-Rifai RH, Majeed M, Qambar MA, Ibrahim A, AlYammahi KM, Aziz F. Type 2 diabetes and pre-diabetes mellitus: a systematic review and meta-analysis of prevalence studies in women of childbearing age in the Middle East and North Africa, 2000-2018. Syst Rev. 2019;8(1):268. doi: 10.1186/s13643-019-1187-1. [PubMed: 31703716]. [PubMed Central: PMC6839168].

15. Everett E, Mathioudakis N. Update on management of diabetic foot ulcers. Ann N Y Acad Sci. 2018;1411(1):153. doi:10.1111/nyas.13569. [PubMed: 29377202]. [PubMed Central: PMC5793889].

16. Malyar NM, Freisinger E, Meyborg M, Luders F, Gebauer K, Reinecke $\mathrm{H}$, et al. Amputations and mortality in in-hospital treated patients with peripheral artery disease and diabetic foot syndrome.J Diabetes Complications. 2016;30(6):1117-22. doi: 10.1016/j.jdiacomp.2016.03.033. [PubMed: 27118161].

17. Gezawa ID, Ugwu ET, Ezeani I, Adeleye O, Okpe I, Enamino M. Anemia in patients with diabetic foot ulcer and its impact on disease outcome among Nigerians: Results from the MEDFUN study. PLoS One. 2019;14(12). e0226226. doi: 10.1371/journal.pone.0226226. [PubMed: 31846473]. [PubMed Central: PMC6917259].

18. Rigato M, Pizzol D, Tiago A, Putoto G, Avogaro A, Fadini GP. Characteristics, prevalence, and outcomes of diabetic foot ulcers in Africa. A systemic review and meta-analysis. Diabetes Res Clin Pract. 2018;142:63-73. doi: 10.1016/j.diabres.2018.05.016. [PubMed: 29807105].

19. World Health Organization. Ambulatory Care Sensitive Conditions in Germany. Copenhagen: WHO Regional Office for Europe; 2015.

20. Ziari A, Ansari M, Valinejadi A. The gap between the service quality and patients' expectations in amir-al-momenin hospital of Semnan university of medical sciences in 2016, Semnan, Iran. Koomesh. 2018:221-7.

21. Bodenheimer T, Berry-Millett R. Care management of patients with complex health care needs. Policy. 2009;1(6).

22. Christovam BP, Porto IS, de Oliveira DC. [Nursing care management in hospital settings: the building of a construct]. Rev Esc Enferm USP. 2012;46(3):734-41. Portuguese. doi: 10.1590/s008062342012000300028. [PubMed: 22773497].

23. Bauer UE, Briss PA, Goodman RA, Bowman BA. Prevention of chronic disease in the 21st century: elimination of the leading preventable causes of premature death and disability in the USA. Lancet. 2014;384(9937):45-52. doi: 10.1016/s0140-6736(14)60648-6.

24. Gitarja WS, Jamaluddin A, Hasyim A, Wibisono V, Megawati N, Fajar $K$. Wound care management in Indonesia: issues and challenges in diabetic foot ulceration. Wounds Asia. 2018;1(2):13-7.

25. Abbas ZG. Managing the diabetic foot in resource-poor settings: challenges and solutions. Chronic Wound Care Manag Res. 2017;4:135-42. doi: 10.2147 /cwcmr.S98762.

26. Healy SJ, Black D, Harris C, Lorenz A, Dungan KM. Inpatient diabetes education is associated with less frequent hospital readmission among patients with poor glycemic control. Diabetes Care. 2013;36(10):2960-7. doi: 10.2337/dc13-0108. [PubMed: 23835695]. [PubMed Central: PMC3781555].

27. Pemayun TG, Naibaho RM, Novitasari D, Amin N, Minuljo TT. Risk factors for lower extremity amputation in patients with diabetic foot ulcers: a hospital-based case-control study. Diabet Foot An- kle. 2015;6:29629. doi: 10.3402/dfa.v6.29629. [PubMed: 26651032] [PubMed Central: PMC4673055].

28. Beiranvand S, Fayazi S, Asadizaker M, Latifi SM. [Survey of the foot care status in type II diabetic patients: application of the theory of Planned Behavior]. J Clin Nurs Mid. 2014;3. Persian.

29. Captieux M, Pearce G, Parke HL, Epiphaniou E, Wild S, Taylor SJC, et al. Supported self-management for people with type 2 diabetes: a meta-review of quantitative systematic reviews. BMJ Open. 2018;8(12). e024262. doi: 10.1136/bmjopen-2018-024262. [PubMed: 30552277]. [PubMed Central: PMC6303627].

30. Golden SH, Maruthur N, Mathioudakis N, Spanakis E, Rubin D, Zilbermint M, et al. The Case for Diabetes Population Health Improvement: Evidence-Based Programming for Population Outcomes in Diabetes. Curr Diab Rep. 2017;17(7):1-17. doi: 10.1007/s11892-017-0875-2. [PubMed: 28567711]. [PubMed Central: PMC5553206].

31. Esteghamati A, Larijani B, Aghajani MH, Ghaemi F, Kermanchi J, Shahrami A, et al. Diabetes in Iran: Prospective Analysis from First Nationwide Diabetes Report of National Program for Prevention and Control of Diabetes (NPPCD-2016). Sci Rep. 2017;7(1):1-10. doi 10.1038/s41598-017-13379-z. [PubMed: 29044139]. [PubMed Central PMC5647418].

32. Ershad Sarabi R, Mokhtari Z, Naghibzadeh Tahami A, Borhaninejad VR, Valinejadi A. Assessment of type 2 diabetes patients' self-care status learned based on the national diabetes control and prevention program in health centers of a selected city, Iran. Koomesh. 2021;23(4):465-73. doi: 10.52547/koomesh.23.4.465.

33. Alirezaei Shahraki R, Aliakbari Kamrani A, Sahaf R, Abolfathi Momtaz Y. Effects of Nationwide Program for Prevention and Control of Diabetes Initiated by the Ministry of Health on Elderly Diabetic Patients' Knowledge, Attitude and practice in Isfahan. Salmand. 2019:8495. doi: 10.32598/sija.14.1.84.

34. Mikkola P, Lehtinen E. Drawing conclusions about what coparticipants know: Knowledge-probing question-answer sequences in new employee orientation lectures. Discourse Commun. 2019;13(5):516-38. doi: 10.1177/1750481319847361.

35. Graneheim UH, Lundman B. Qualitative content analysis in nursing research: concepts, procedures and measures to achieve trustworthiness. Nurse Educ Today. 2004;24(2):105-12. doi: 10.1016/j.nedt.2003.10.001. [PubMed: 14769454].

36. El Hussein M, Jakubec S, Osuji J. Assessing the FACTS: A Mnemonic for Teaching and Learning the Rapid Assessment of Rigor in Qualitative Research Studies. Qual Rep. 2015. doi: 10.46743/2160-3715/2015.2237.

37. Smith-Strom H, Iversen MM, Igland J, Ostbye T, Graue M, Skeie S, et al. Severity and duration of diabetic foot ulcer (DFU) before seeking care as predictors of healing time: A retrospective cohort study. PLoS One. 2017;12(5). e0177176. doi: 10.1371/journal.pone.0177176. [PubMed: 28498862]. [PubMed Central: PMC5428931].

38. Bus SA, van Netten JJ, Lavery LA, Monteiro-Soares M, Rasmussen A, Jubiz Y, et al. IWGDF guidance on the prevention of foot ulcers in at-risk patients with diabetes. Diabetes Metab Res Rev. 2016;32 Suppl 1:16-24. doi: 10.1002/dmrr.2696. [PubMed: 26334001].

39. Nang EEK, Dary C, Hsu LY, Sor S, Saphonn V, Evdokimov K. Patients' and healthcare providers' perspectives of diabetes management in Cambodia: a qualitative study. BMJ Open. 2019;9(11). e032578. doi: 10.1136/bmjopen-2019-032578. [PubMed: 31753894]. [PubMed Central: PMC6887069].

40. Orneholm H, Apelqvist J, Larsson J, Eneroth M. High probability of healing without amputation of plantar forefoot ulcers in patients with diabetes. Wound Repair Regen. 2015;23(6):922-31. doi: 10.1111/wrr.12328. [PubMed: 26084518].

41. Ebrahimian A, Khalesi N, Tourdeh M. Continuing education of intensive and emergency units nurses during clinical shifts. HealthMED. 2012;6(10):3346-50.

42. Mohammadi G, Tourdeh M, Ebrahimian A. Effect of simulationbased training method on the psychological health promotion in 
operating room students during the educational internship. J Educ Health Promot. 2019;8. doi: 10.4103/jehp.jehp_106_19. [PubMed Central: PMC6796314].

43. Honey M, Procter P. The Shifting Sands of Nursing Informatics Education: From Content to Connectivity. Stud Health Technol Inform. 2017;232:31.

44. Bain SC, Cummings MH, McKay GA. Multidisciplinary Approach to
Management and Care of Patients with Type 2 Diabetes Mellitus. Diabetes. 2019.

45. Foo KM, Sundram M, Legido-Quigley H. Facilitators and barriers of managing patients with multiple chronic conditions in the community: a qualitative study. BMC Public Health. 2020;20(1):273. doi: 10.1186/s12889-020-8375-8. [PubMed: 32106838]. [PubMed Central: PMC7045577]. 